\title{
Is this the way to
}

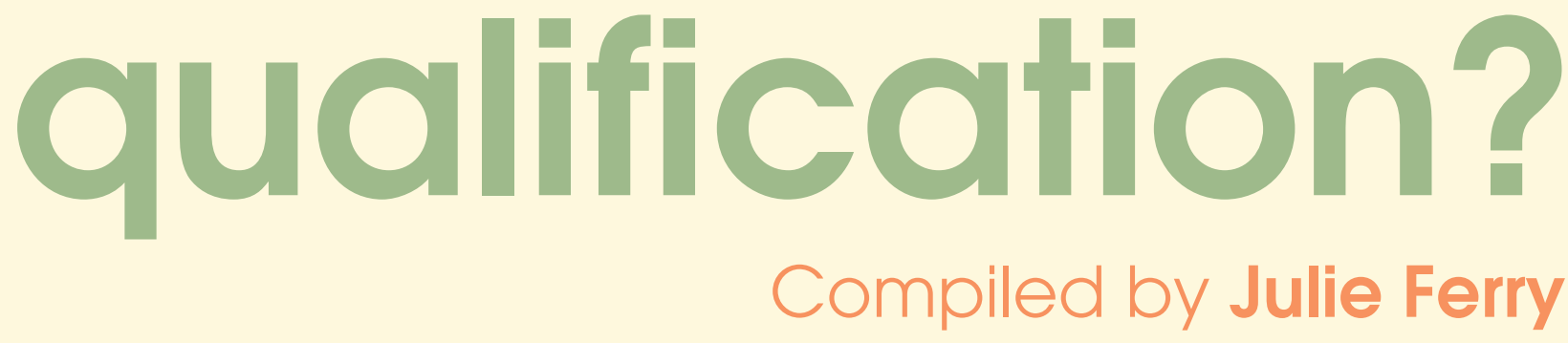

Recently there has been an explosion in the number of courses available to DCPs. With increased recognition for the team, providers have realised that they must adapt to fulfill your training needs, ranging from basic skills to integrated courses with dentists, full-time courses to flexible learning. There has also been a push from institutions to include DCPs in the training of the dentists of the future; competition to provide the ultimate course has heated up. But where does all this change leave DCPs?

If you are keen to see your career progress there has never been a better time. As there is so much choice, Vital has decided to help you decipher the maze. This list isn't exhaustive but it should give you a starting point to find out what is available in your area.

\section{SOUTH-EAST}

\section{GKT}

The newly established DCP Centre for Education and Learning at GKT recognises the vital role of DCPs and encompasses the education and learning of dental nurses, hygienists and therapists.

In October 2001, the Guy's and St Thomas' Trust and the King's College Hospital Schools of Dental Nursing merged to become GKT Dental Nurse Education \& Training Centre, one of the largest dental nurse training providers in the country. Both the National Vocational Qualification (NVQ) Level 3 in Oral Healthcare Dental Nursing and the Certificate of the National Examining Board for Dental Nurses are available courses for dental nurse training.

Dental Hygiene and Therapy Diplomas are also available at GKT and students are encouraged to use reflective and problem-based approaches to learning, rather than the traditional didactic teaching methods of the past. There is a team-working approach and clinical experience is gained at both the Denmark Hill Campus and the Guy's Campus. Students also go into the community and to other clinics to gain further clinical experience.

www.kcl.ac.uk/dentistry/study/pcd.html Tel: 02073461611

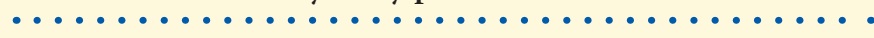

\section{Barts and The London}

The Centre for Professionals Complementary to Dentistry at Barts and The London teaches dental nurses, hygienists and therapists. Much of the training takes place alongside dental undergraduate and postgraduate students, enhancing the Dental Institute's team approach to education. Courses available include the NVQ Oral Health Care (Dental Nursing course), Certificate in Oral Health Education and Diplomas in Dental Hygiene and Therapy.

www.smd.qmul.ac.uk/undergraduate/pcd/index.html Tel: 02073777634

\section{The Eastman}

The Eastman is generally known for its excellence in training. The school has been awarded the highest grades in five out of six categories of independent educational quality assurance. It has first-class facilities for both education and research which provide unique, seamless training. The Eastman offers a Diploma in Dental Hygiene and a Diploma in Dental Hygiene and Therapy. Competition for the NHS-funded places is very high with only 10 students being accepted onto the Therapy course and 14 students onto the Hygiene course each year. The Eastman also offers a range of dental nurse training courses.

www.eastman.ucl.ac.uk Tel: 02079151205

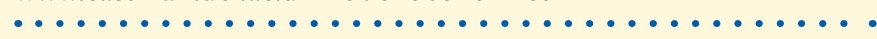

\section{Portsmouth}

The School of Professionals Complementary to Dentistry is the first of its kind in the country and was developed by the University of Portsmouth in partnership with the Hampshire and Isle of Wight NHS Workforce Development Confederation. The School offers three programmes of study and demand for places is extremely high. The courses are:

- Foundation Programme in Science and Dental Therapy

- BSc (Hons) Dental Hygiene and Dental Therapy

- CertHE Dental Nursing Certificate of Higher Education (CertHE) in Dental Nursing.

A brand new building providing purpose-built clinical and academic facilities opened in February 2005. The building includes a 24-bay treatment clinic, two private surgeries, a phantom head room, radiography suite and general teaching rooms.

www.port.ac.uk/departments/academic/dentistry/ Tel: 02392845281

\section{Technician courses in the South-East}

Lambeth College in South London provides a dental technician course. www.lambethcollege.ac.uk Tel: 02075015830 


\section{education:}

-Dundee

- Newcastle upon Tyne

-Belfast
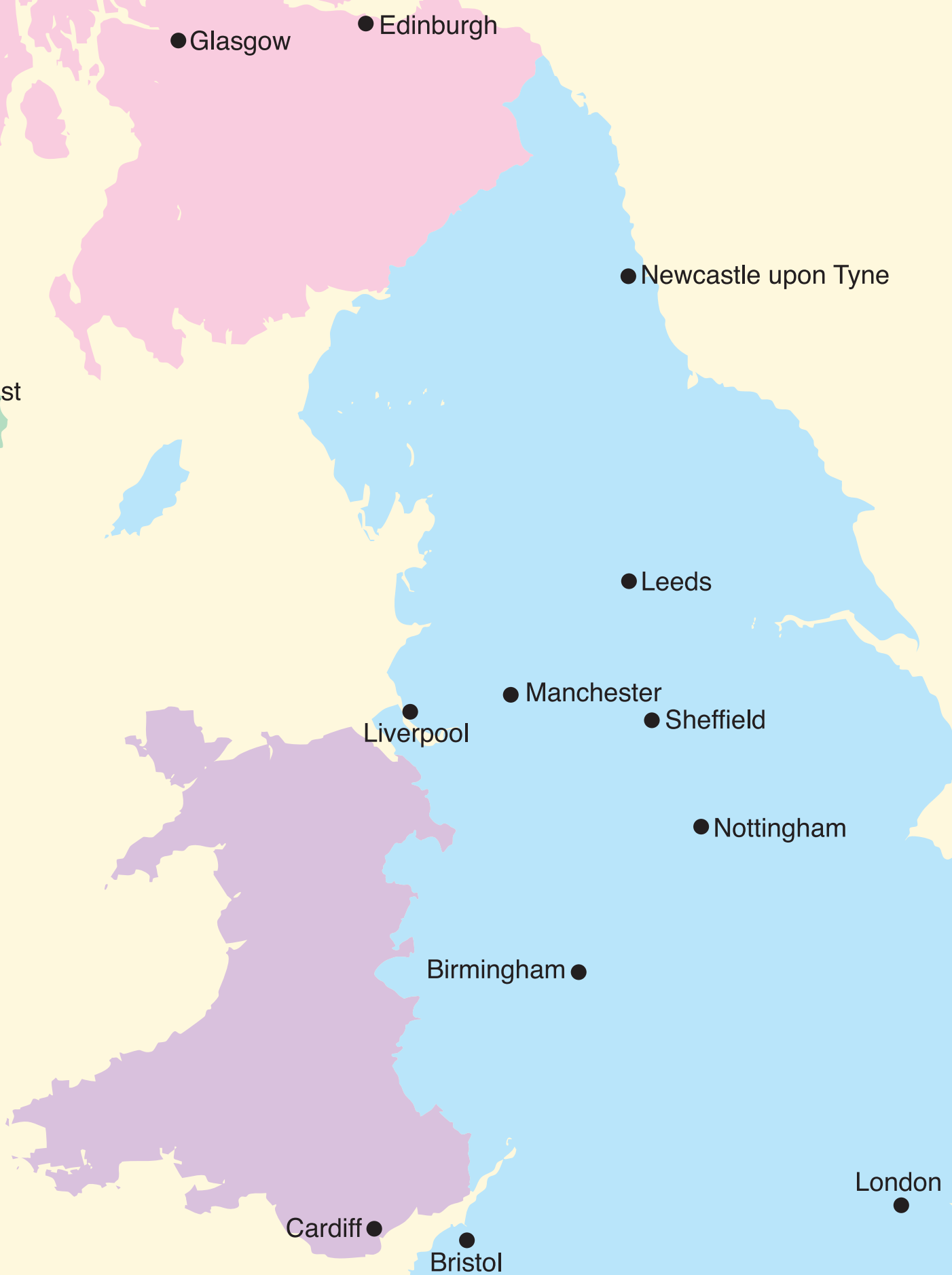
Southampton City College also offers a dental technician qualification. www.southampton-city.ac.uk Tel: 02380577230

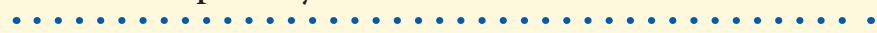

\section{SOUTH-WEST}

\section{Bristol}

Bristol Dental Hospital will offer a new combined Dental Hygiene and Dental Therapy programme from January 2007. Twelve students will be accepted onto the course and can expect to enjoy multi-disciplinary clinics, shared clinical and didactic teaching with dental students and the opportunity to experience outreach facilities. Between 2005 and 2008 Bristol Dental Hospital will be undergoing a period of significant growth with the improvement of teaching facilities, the redevelopment of the current site and an increase in dental chair numbers just some of the plans.

\section{www.dentalschool.bris.ac.uk Tel: 01179289000}

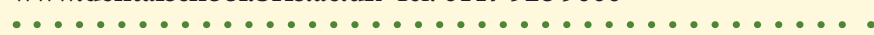

The School for Dental Nurse Education at Bristol Dental Hospital offers a number of different courses, including a 24-month full-time course which leads to the National Examination in Dental Nursing and then the National Certificate in Dental Nursing.

www.dentalschool.bris.ac.uk/departments/nursing_hygiene/ Tel: 01179284131

\section{WALES}

\section{Cardiff}

At Cardiff University Dental School you can study for a diploma in Dental Hygiene, a combined diploma in Dental Hygiene and Dental Therapy, or an NVQ in Dental Nursing. Dental Hygiene and Dental Therapy courses are available in the Training and Education Centre for DCPs and the Dental Nursing course is provided by Cardiff \& Vale NHS Trust.

The Training and Education Centre for DCPs (DCPTEC) is part of Cardiff School of Dentistry and is an integral part of the department of Adult Dental Health. The department is committed to the development of high quality dental education for the dental team, and the DCPTEC provides a focus for much of this team education.

The DCPTEC has trained hygienists since 1969, and offers a Diploma in Dental Hygiene as a two-year programme. The Diploma in Therapy was started in 1996, however, from September 2003, these two diplomas were combined into one, and the DCPTEC now offers a combined diploma in Dental Hygiene and Dental Therapy. The joint qualification allows graduating students to register with the GDC.

www.cardiff.ac.uk/dentistry/school/adh/pcdtec Tel: 02920744251

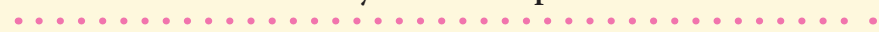

University of Wales Institute, Cardiff offers several dental technician course options, including the National Certificate, HNC and BSc in Dental Technology.

www.uwic.ac.uk Tel: 02920416899

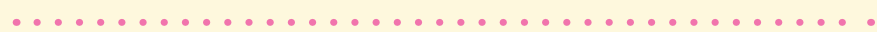

\section{MIDLANDS}

\section{Birmingham}

Birmingham offers an integrated BSc course leading to a qualifi- cation in both Dental Hygiene and Dental Therapy. The course is full time and lasts for three years and on qualification the graduate is eligible to apply for entry to the GDC's DCP register. Students are based at Birmingham Dental Hospital and School where the basic skills are acquired.

Clinical work begins early in the second term and throughout the course clinical practice is juxtaposed with lectures, small group teaching and self-directed learning. Patients are treated under the supervision of a tutor and graded as part of the continuous assessment process. Integrated teaching and learning with undergraduate dental students in the clinical practice setting is a major component in fostering the team approach to dentistry. Second and third year students undertake a major component of the clinical practice in outreach clinics within the West Midlands.

The School of Dental Hygiene \& Therapy has excellent teaching facilities with up-to-date audiovisual and computer equipment. Oral Health Promotion forms an integral part of the course and students visit nurseries and schools to teach oral health to children and young people.

www.dentistry.bham.ac.uk Tel: 01212368611

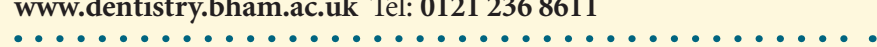

Technician courses in the West Midlands

Matthew Boulton College in Birmingham offers a dental technician course.

www.matthew-boulton.ac.uk Tel: 01214464545

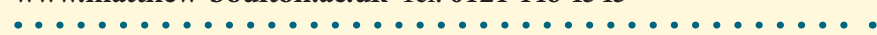

People's College in Nottingham also offers a qualification for dental technicians.

www.peoples.ac.uk Tel: 01159123444

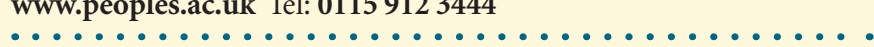

\section{NORTH-EAST}

\section{Leeds}

The Leeds Dental Institute offers in-house training to all members of the dental team: dentists (at the undergraduate and postgraduate levels), dental hygienists, dental therapists, dental technicians and dental nurses. Increasingly, wherever possible, students are taught together as a dental team. The range of courses on offer for PCDs includes:

- Graduate Diploma in Dental Hygiene \& Dental Therapy

- BTEC National Diploma in Dental Technology

- The NVQ Oral Health Care Dental Nursing level 3

- The National Certificate for Dental Nurses.

\section{www.leeds.ac.uk/dental/contacts2.html Tel: 01133436172}

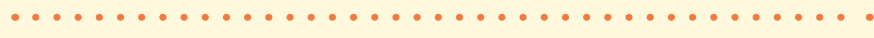
Sheffield

The Diploma in Dental Hygiene and Dental Therapy is a 27-month diploma course and has been offered by Sheffield University since 1996. The course is constantly evolving and kept under continual review to ensure that current accepted practices are being taught. There is a strong belief at the school in integrating the dental hygienists and therapists with the dental students. The school allocates a personal tutor to each student and is committed to providing feedback throughout the course.

www.shef.ac.uk/dentalschool/

Tel: 01142717801 
Sheffield College provides a dental technician's course. www.sheffcol.ac.uk Tel: 01142602059

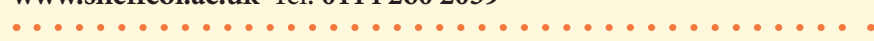

\section{Newcastle}

Newcastle Dental School has just developed a new Diploma in Dental Hygiene and Therapy, which will begin in September 2006. After many months of preparation the school is very excited about this new development. Diploma students can look forward to integrated lectures and clinical skills courses with dental students and the main focus of the school will be on the whole dental team. The school also provides an NVQ course in dental nursing.

www.newcastle.ac.uk/dental Tel: 01912228347

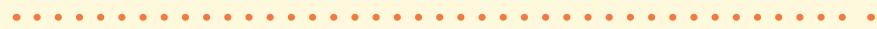

\section{NORTH-WEST}

\section{Manchester}

Manchester dental school introduced the BSc in Oral Health Science in September 2000 in response to a need to develop a new class of clinical personnel — the Oral Health Therapist — who combines the existing skills of hygienists and therapists and provides a holistic approach to primary dental care.

During the course students will learn all of the clinical duties that are required of an Oral Health Therapist, including periodontal treatment, simple fillings, extraction of primary teeth and dental radiographs. www.dentistry.manchester.ac.uk Tel: 01613060220

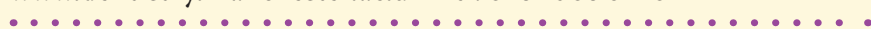

Manchester Metropolitan University offers several dental technician course options, including the national certificate, HNC and BSc in Dental Technology.

www.chem-mats.mmu.ac.uk Tel: 01612471441

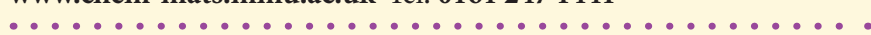

\section{Liverpool}

Liverpool Dental School offers a Combined Diploma in Dental Hygiene and Dental Therapy, which aims to produce caring, knowledgeable, competent and skilful Diploma holders.

The Diploma is a full-time modular course which is studied over 27 calendar months, with students based at one of four sites: Blackburn, Crewe, Lancaster and Liverpool. Currently, the annual intake for this course is 34 students (10 at Blackburn, six at Crewe, eight at Lancaster and 10 at Liverpool).

The Dental Nursing course held at the Liverpool University Dental Hospital is a two-year course, which includes a three-week introduction to anatomy, bacteriology, chairside assisting, health and safety at work, charting and instrumentation. Clinical duties are also assigned at this time, to enable the dental nurse to experience the practical aspects of the job.

www.liv.ac.uk Tel: 01517065203

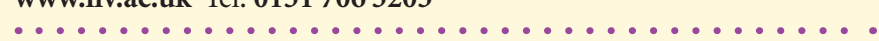

Liverpool Community College offers a course for dental technicians. www.liv-coll.ac.uk Tel: 01512524862

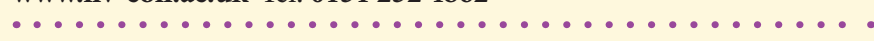

\section{SCOTLAND}

\section{Dundee}

The BSc course in Oral Health Sciences offered at the University of Dundee was the first combined University Dental Hygiene and Dental Therapy qualification to be introduced in Scotland. Teaching is provided mainly in the Dental School and Hospital but also at Ninewells Hospital and in regional community clinics.

The course takes place over two semesters for three years. It comprises 17 modules and a total of 360 credits.

www.dundee.ac.uk/dentalschool

Tel: 01382 635976/7

\section{Edinburgh}

The course in dental hygiene has been discontinued and is being replaced by a new combined course in Dental Hygiene and Dental Therapy, which will begin in March 2007. The course and entry requirements have not yet been finalised so please contact the school for more details.

Edinburgh also provides a two-year comprehensive course in dental nursing based at the Dorothy Melville School of Dental Nursing, which opened in October 2001. The course covers all aspects of dental nursing, both theoretical and practical, and is hospital and community based. It leads to a certificate of proficiency and also enables students to take the National Certificate for Dental Nurses.

www.epdi.org.uk/pcd Tel: 01315364961

Telford College provides a technician's course. www.ed-coll.ac.uk Tel: 01313157355

\section{Glasgow}

Glasgow PCD School prides itself on working very closely with Glasgow Dental School. Consequently there is a lot of integration with dental students, particularly for hygiene and therapy students. Glasgow offers a combined Diploma in Dental Hygiene and Therapy, which it introduced as part of a Scottish Executive initiative in October 2003. The Diploma is presently awarded by the Royal College of Surgeons, Edinburgh, but it is hoped that in the future the school will receive accreditation for the course to become a three-year degree programme. There is also a two-year dental nurse training course available at the school.

Tel: 01412119775

Langside College offers a dental technician course.

www.langside.ac.uk Tel: 01412723814

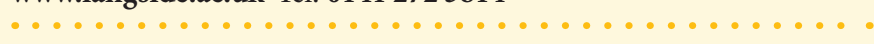

\section{NORTHERN IRELAND}

\section{Belfast}

Belfast currently offers training for hygienists and dental nurses. The School of Dentistry is one of 14 dental schools in the United Kingdom and one of three in Ireland. The School has a core ethos of high quality patient care where the clinical service, teaching and research are integrated to ensure excellence in all three areas.

www.qub.ac.uk/cd/ Tel: 02890263244

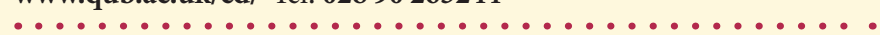

Belfast also offers a dental technician course.

www.royalhospitals.n-1.nhs.uk

Tel: 02890236013 